УДК 549.67

\title{
Hydrothermal Synthesis \\ of Zeolite with Structure of W
}

\author{
Gyunel A. Mamedova* \\ Nakhchivan Branch of the National Academy \\ of Sciences Institute of Natural Resources of Azerbaijan \\ 76 Heydar Aliyev avenue, AZ7000, Nakhchivan, Azerbaijan
}

Received 18.05.2017, received in revised form 12.08.2017, accepted 17.11.2017

One of the most important objectives of the research of crystallization processes of zeolites is the creation of materials with predetermined structure and composition. Based on the natural mineral of deposit of Nakhchivan a zeolite of the potassium-containing type $W$ was synthesized. The synthesis was carried out in hydrothermal conditions, in a temperature range of $150-250{ }^{\circ} \mathrm{C}$, at the variation of the potassium hydroxide concentration in the range 1-3 $N$ for 3-5 days. The optimum conditions for obtaining a zeolite of type $\mathrm{W}$ are the temperature of $150{ }^{\circ} \mathrm{C}$, the concentration of $\mathrm{KOH}$ solution of $1 \mathrm{~N}$, the treatment time is 3 days. The initial sample and resulting zeolite was investigated by X-ray diffraction, thermogravimetric, IR-spectroscopic methods and by elemental analysis. According to the $X$-ray data zeolite of $W$ crystallizes in a cubic system with a unit cell parameter $a=20.1$ A.

Keywords: hydrothermal synthesis, zeolite of W, natural mineral, structure, elemental composition, properties.

DOI: $10.17516 / 1998-2836-0051$.

(C) Siberian Federal University. All rights reserved

* Corresponding author E-mail address: gunelmamadova@mail.ru 


\section{Гидротермальный синтез цеолита со структурой W}

Г.А. Мамедова

Нахчыванское отделение НАН Азербайджана

Институт природных ресурсов

Азербайджан, Az 7000, г. Нахчыван, пр. Гейдара Алиева, 76

Одной из наиболее важных иелей исследования процессов кристаллизации цеолитов является создание материалов с заранее заданными структурой и составом. На основе природного минерала месторождения Нахчывана был синтезирован цеолит типа калийсодержащего $W$. Синтез был проведен в гидротермальных условиях, в температурном интервале 150-250 ${ }^{\circ} \mathrm{Cnpи}$ вариации концентрации гидроксида калия в интервале 1-3 N, в течение 3-5 сут. Оптимальные условияполучениячеолитатипа $\mathrm{W}$-температура $150^{\circ} \mathrm{C}$, концентрацияраствора $\mathrm{KOH} 1 \mathrm{~N}$, время обработки 3 сут. Исходный образец и полученный цеолит исследованы рентгенографическим, термогравиметрическим, ИК-спектроскопическим методами и элементным анализом. По данным рентгенографического анализа, цеолит $W$ кристаллизуется в кубической сингонии с параметром элементарной ячейки $a=20.1$ А.

Ключевые слова: гидротермальный синтез, цеолит $W$, природный минерал, структура, элементный состав, свойства

\section{Введение}

Получение цеолитов различных структурных типов [1] и создание широкого спектра молекулярных сит [2] на основе местных минеральных ресурсов - актуальные задачи в химии цеолитов. Значительное влияние на адсорбционные свойства (адсорбционную емкость, ситовой эффект, селективность) цеолитов оказывает химическая модификация [3-6]. С ее помощью можно влиять на структуру цеолитов и получать минералы цеолитовой группы [7] с требуемыми параметрами.

Преимуществом гидротермального метода является высокая степень смешения реагентов, относительно мягкие условия синтеза (температура $<350{ }^{\circ} \mathrm{C}$ ), возможность контроля фазового состава получаемых продуктов [3, 7].

Цель данного исследования - разработка гидротермального метода синтеза цеолита со структурой $\mathrm{W}$ из природного цеолита месторождения Нахчывана и изучение его строения и свойств.

\section{Материалы и методы}

В качестве образцов служили цеолитовые туфы Нахчывана, 78,5 \% которого составляет основной минерал морденит, 19,5 \% - кварц и 2,0 \% - анортит. Образец цеолита был взят из цеолитсодержащего горизонта на северо-западе р. Кюкючай, где его содержание колеблется 
в пределах 75-80\%. Образец тщательно промывали дистиллированной водой и сушили при $150{ }^{\circ} \mathrm{C}$ в течение 3 ч.

Гидротермальный синтез проводили в автоклавах типа Мори объемом 18 см$^{3}$, изготовленных из нержавеющей стали марки 45МНФТ, коэффициент заполнения автоклавов $\mathrm{F}=0.8$. Опыты по гидротермальной кристаллизации проводились без перемешивания реакционной массы. Отношение твердой фазы к жидкой 1:10.

Эксперименты по гидротермальному синтезу цеолита типа W проводили в течение 3-5 сут, в температурном интервале $150-250{ }^{\circ} \mathrm{C}$. В качестве растворителя для обработки твердой шихты использовались растворы гидроксида калия различной концентрации (от 1 до 3 N). По окончании эксперимента автоклав закалялся в проточной воде. Затем полученные продукты отфильтровывали, промывали до $\mathrm{pH}=8$, сушили при температуре $80^{\circ} \mathrm{C}$ и подвергали дальнейшим исследованиям.

Фазовый и химический состав исходного и конечного продуктов определяли рентгенографическим (2D PHASER «Bruker» $\left(\mathrm{CuK}_{\alpha-}\right.$ излучение, $\left.2 \theta=20-80^{\circ}\right)$ и элементным (Launch of Trition XL ditution refrigerator - Oxford instrument) методами анализа. Термогравиметрический анализ образцов проводился на «Q-Дериватографе 1500-Д» венгерской фирмы МОМ в динамическом режиме в области температур 20-1000 ${ }^{\circ} \mathrm{C}$. Режим съемки: скорость нагрева 10 \%мин; скорость движения бумаги 2,5 мм/мин; чувствительность ДТА, ТГ равна 500 мв; керамические тигли; эталон $-\mathrm{Al}_{2} \mathrm{O}_{3}$. Элементный анализ проводили в аппарате Launch of Trition XL ditution refrigerator - Oxford instrument. Навеску исследуемого образца гомогенизировали сплавлением, затем их готовили в виде прессованных дисков диаметром 40 мм на подложке из борной кислоты. В качестве эталонных образцов использовали смесь химических реактивов $\mathrm{Al}_{2} \mathrm{O}_{3}$ и $\mathrm{SiO}_{2}$, в качестве источника возбуждения - рентгеновскую трубку, высокое напряжение до 8 кB, гелиевую продувку, вращатель образцов, систему селективных фильтров Focus S, которая улучшает эффективное разрешение и обеспечивает более низкие пределы обнаружения. ИК-спектроскопические исследования проводили на ИК-спектрометре «Nicolet IS-10» в диапазоне частот 400-5000 $\mathrm{cm}^{-1}$. Образцы полученных цеолитов готовили таблетированием с $\mathrm{KBr}$ на воздухе в соотношении 1 мг образца/400 мг $\mathrm{KBr}$ с помощью ручного пресcа «Spectroscopic Creativity Pike Technologies».

\section{Результаты и их обсуждение}

На основе элементного анализа установлен химический состав морденита в исходном образце:

$$
\mathrm{Ca}_{2} \mathrm{Na}_{2} \mathrm{~K}_{2,8} \mathrm{Al}_{8,8} \mathrm{Si}_{39,2} \mathrm{O}_{96} \cdot 34 \mathrm{H}_{2} \mathrm{O} \text {. }
$$

Согласно рентгенографическому анализу установлено, что морденит в исходном образце кристаллизуется в орторомбической сингонии с параметрами a=18,094 $\AA$; $b=20,516$ $\AA ;$; $=7,524 \AA$.

Рентгенографические данные порошка синтетического цеолита K-W хорошо согласуются с литературными данными (табл. 1).

Из табл. 1 видно, что межплоскостные расстояния (d, А̊) образцов известного по литературе и синтезированного нами K-W совпадают, но отличаются между собой относительными

$$
-589-
$$


Таблица 1. Рентгенографические данные синтезированного цеолита $K-W$ и известного по литературе для цеолита $W$

Table 1. The X-ray diffraction data of the synthesized K-W zeolite and the literature data on zeolite W

\begin{tabular}{|c|c|c|c|}
\hline \multicolumn{2}{|c|}{ Литературные данные для цеолита $W[8]$} & $\mathrm{d}, \AA$ & \multicolumn{2}{|c|}{ Синтезированный $K-W$} \\
\hline $\mathrm{d}, \AA$ & $\mathrm{I}_{\text {отн }}$ & 10,06 & $\mathrm{I}_{\text {отн }}$ \\
\hline 9,99 & 20 & 8,15 & 45 \\
8,17 & 49 & 7,04 & 50 \\
7,09 & 54 & 5,34 & 25 \\
5,34 & 28 & 4,99 & 45 \\
5,01 & 56 & 4,49 & 20 \\
4,45 & 21 & 4,27 & 25 \\
4,28 & 35 & 4,08 & 25 \\
4,05 & 30 & 3,78 & 20 \\
3,77 & 20 & 3,68 & 20 \\
3,64 & 20 & 3,47 & 15 \\
3,47 & 15 & 3,25 & 100 \\
3,25 & 100 & 3,17 & 70 \\
3,17 & 75 & 2,95 & 65 \\
2,95 & 71 & 2,72 & 50 \\
2,72 & 53 & 2,67 & 10 \\
2,67 & 12 & 2,54 & 15 \\
2,54 & 26 & 2,08 & 8 \\
2,08 & 10 & 1,67 & 5 \\
1,66 & 7 & & \\
\hline
\end{tabular}

интенсивностями $\left(\mathrm{I}_{\text {отн }}\right)$ дифракционных линий. Как известно, хорошо окристаллизованный материал дает узкие высокие дифракционные линии, плохо окристаллизованный материал - широкие и низкие линии. Так как полученный нами цеолит K-W малокристалличен, это оказывает влияние на интенсивность дифракционных линий.

По данным рентгенографического анализа, цеолит W кристаллизуется в кубической сингонии с параметром a=20.1 $\AA$, что хорошо согласуется с литературными данными $[8,9]$. Согласно элементному анализу установлена эмпирическая формула цеолита типа K-W:

$$
\mathrm{K}_{10,32} \mathrm{Al}_{10,3} \mathrm{Si}_{39,7} \mathrm{O}_{64} \cdot 24,32 \mathrm{H}_{2} \mathrm{O} \text {. }
$$

Рентгенограммы исходного образца Нахчывана и синтезированного на его основе цеолита W изображены на рис. 1.

Элементный состав природного образца цеолита представлен на рис. 2 и в табл. 2, а процентное содержание оксидов в составе полученного цеолита K-W - в табл. 3.

Методом термографического анализа установлена область дегидратации, содержание воды и термостабильность К-W. Кривые дифференциально-термического анализа (ДТА) и термогравиметрии (ТГ) изображены на рис. 3.

На ДТА отмечены эндотермический и экзотермический эффекты. Эндотермический эффект с максимумом при $195{ }^{\circ} \mathrm{C}$ относится к дегидратации образца, потеря массы при этом составляет $14.8 \%$.

Экзотермический эффект при температуре $680^{\circ} \mathrm{C}$, по данным рентгенофазового анализа, относится к разрушению кристаллической структуры цеолита $\mathrm{W}$.

$$
-590-
$$



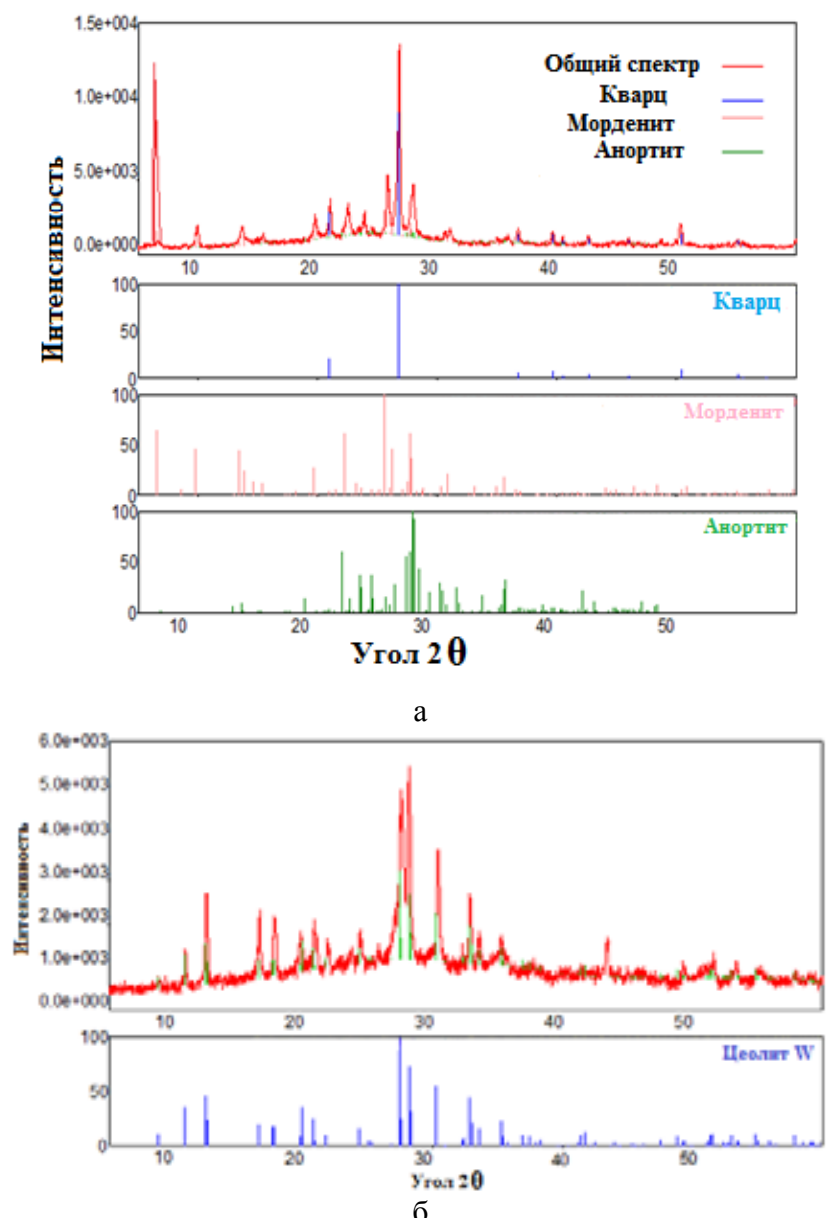

Рис. 1. Дифрактограмма исходного образца Нахчывана (а) и синтезированного цеолита W (б) Fig.1. X-ray patterns of the initial sample of Nakhchivan (a) and of synthesized zeolite W (b)

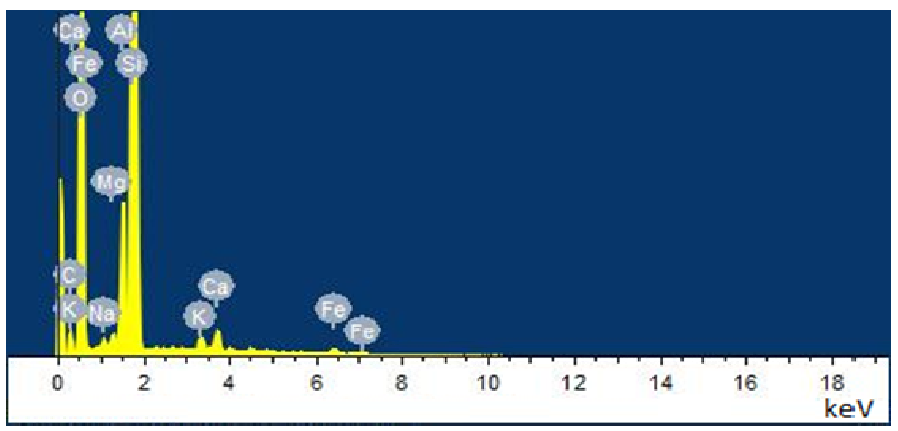

Рис. 2. Элементный состав исходного образца месторождения Нахчывана

Fig. 2. Elemental composition of the initial sample of deposit of Nakhchivan 
Таблица 2. Процентное содержание оксидов и элементов в составе исходного образца Нахчывана

Table 2. Percentage content of oxides and elements in the initial sample of Nakhchivan

\begin{tabular}{|c|c|c|c|c|}
\hline Элемент & Весовой \% & Атомный \% & $\begin{array}{c}\text { Количество } \\
\text { оксидов, \% }\end{array}$ & Формула \\
\hline $\mathrm{Na}$ & 0,42 & 0,37 & 0,56 & $\mathrm{Na}_{2} \mathrm{O}$ \\
$\mathrm{Mg}$ & 0,38 & 0,32 & 0,63 & $\mathrm{Al}_{2} \mathrm{O}_{3}$ \\
$\mathrm{Al}$ & 4,49 & 3,38 & 8,48 & $\mathrm{SiO}_{2}$ \\
$\mathrm{Si}$ & 40,53 & 29,33 & 86,71 & $\mathrm{~K}_{2} \mathrm{O}$ \\
$\mathrm{Ca}$ & 0,75 & 0,39 & 1,59 & $\mathrm{FeO}$ \\
$\mathrm{Fe}$ & 1,14 & 0,58 & 1,12 & \\
\hline
\end{tabular}

Таблица 3. Процентное содержание оксидов и элементов в составе полученного цеолита W

Table 3. Percentage content of oxides and elements in the synthesized zeolite $\mathrm{W}$

\begin{tabular}{|c|c|c|c|c|}
\hline Элемент & Весовой \% & Атомный \% & $\begin{array}{c}\text { Количество } \\
\text { оксидов \% }\end{array}$ & Формула \\
\hline$M g$ & 0,59 & 0,53 & 0,97 & $\mathrm{MgO}_{2}$ \\
$\mathrm{Al}$ & 7,98 & 6,16 & 14,9 & $\mathrm{SiO}_{2}$ \\
$\mathrm{Si}$ & 31,06 & 23,76 & 63,09 & $\mathrm{~K}_{2} \mathrm{O}$ \\
$K$ & 12,15 & 6,73 & 15,48 & $\mathrm{FaO}$ \\
$\mathrm{Ca}$ & 2,49 & 1,37 & 3,48 & 1,57 \\
$\mathrm{Fe}$ & 1,22 & 0,48 & & \\
\hline
\end{tabular}

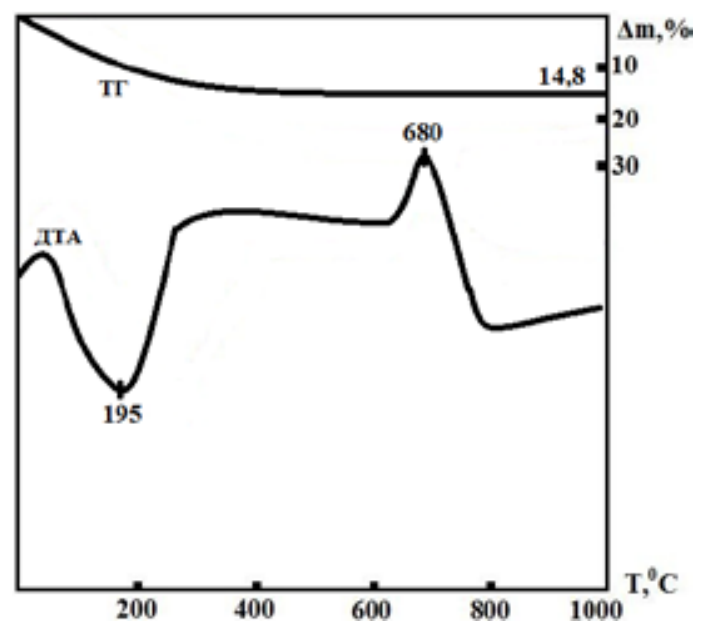

Рис. 3. Кривые ДТА и ТГ цеолита К-W

Fig. 3. DTA and TG curves of zeolite K-W 
Как видно из кривой ДТА, дегидратация происходит в интервале температур 100-300 ${ }^{\circ} \mathrm{C}$. Рентгенофазовый анализ образца после эндоэффекта показал, что структурных изменений не наблюдается. Дегидратированный при $100-300{ }^{\circ} \mathrm{C}$ образец полностью регидратируется в течение 10 ч, т.е. дегидратация носит обратимый характер.

Согласно [10], можно заключить, что в ИК-спектре полосы поглощения в диапазоне частот 250-1400 см$^{-1}$ соответствуют основным колебаниям алюмокремниевых тетраэдров каркасной структуры цеолитов. Наблюдаемые полосы поглощения отнесены к двум типам колебаний: 1 - колебания, характеризующие первичные структурные единицы $-\mathrm{TO}_{4}$, где $\mathrm{T}=\mathrm{Si}^{4+}, \mathrm{Al}^{3+}$, и 2 - колебания $\mathrm{TO}_{4}$-тетраэдров по внешним связям. Второй тип колебаний зависит от характера сочленения тетраэдров во вторичные структурные единицы и особенностей полостей цеолитов. ИК-спектр исходного образца и полученного цеолита K-W представлен на рис. 4.

Как видно на рис. 4, наиболее интенсивные полосы поглощения наблюдаются при 1048.61 и $1049.75 \mathrm{~cm}^{-1}$, они, а также полоса 693.87 см$^{-1}$ отвечают колебаниям связей $\mathrm{Si}-\mathrm{O}-\mathrm{Si}$. Полосы поглощения 796.75 и 778.24 см$^{-1}$ относятся к валентным колебаниям связи $\mathrm{Al}-\mathrm{O}$, а 459.09 и $460.91 \mathrm{~cm}^{-1}$ - к деформационным колебаниям $\mathrm{Al}-\mathrm{O}_{4}$. С наличием цеолитной воды связаны по-

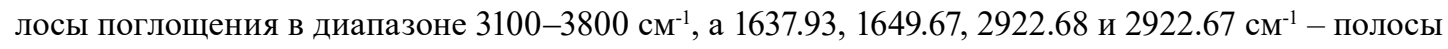
деформационных колебаний молекул воды. Полоса поглощения $2347.64 \mathrm{~cm}^{-1}$ (рис. $4 a$ ) объясняется присутствием карбонатов в составе природного образца. Малая интенсивность полосы

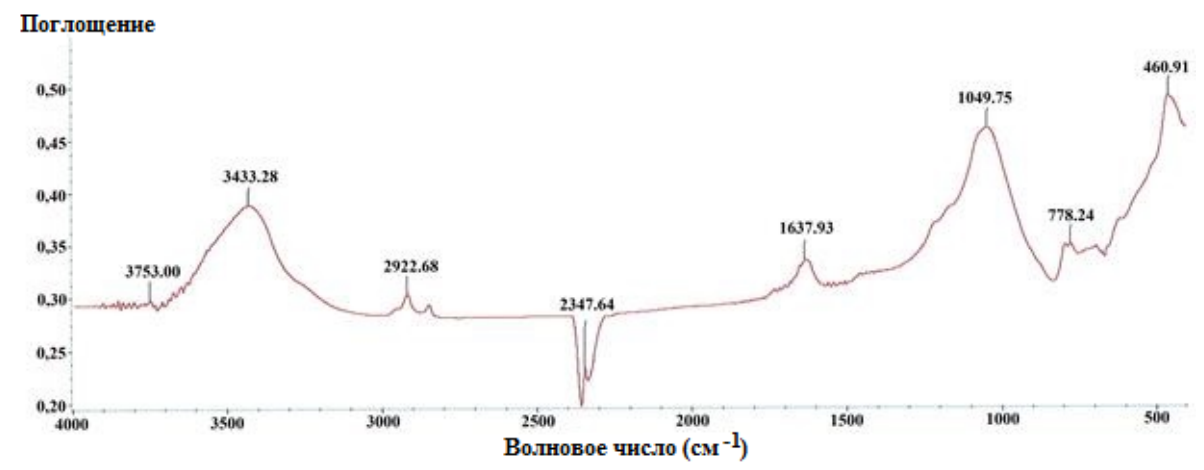

a

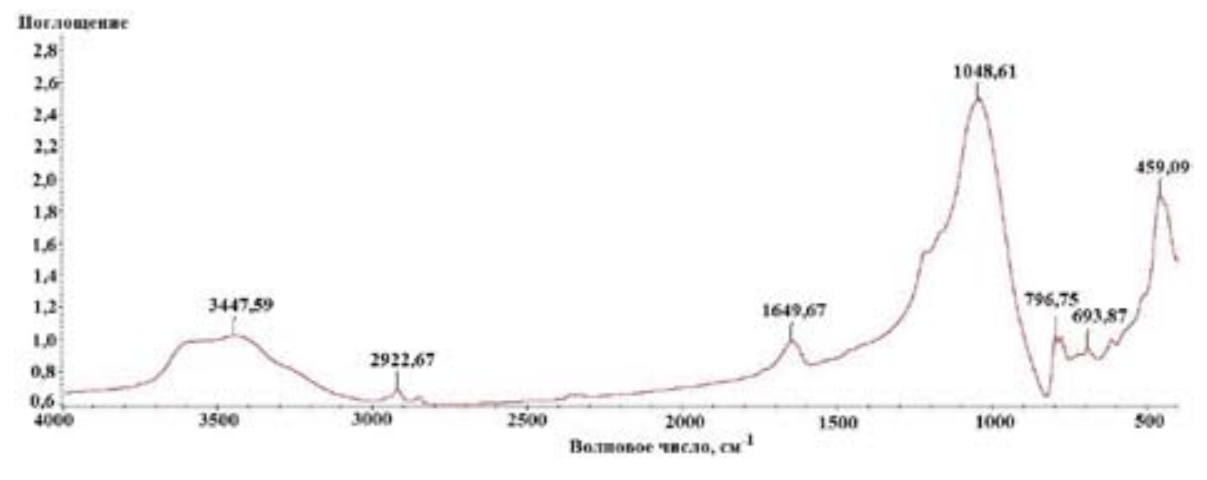

6

Рис. 4. ИК-спектр исходного образца Нахчывана (а) и полученного цеолита K-W (б)

Fig. 4. IR-spectra of the initial sample of Nakhchivan (a) and of the obtained zeolite R-W (b) 
поглощения $459.09 \mathrm{~cm}^{-1}$ свидетельствует о низкой кристалличности полученного цеолита K-W, что также видно из дифрактограммы продукта (рис. 16).

\section{Заключение}

Впервые на основе природного образца месторождения Нахчывана гидротермальным методом был синтезирован цеолит K-W. Установлены оптимальные условия синтеза цеолита $\mathrm{K}-\mathrm{W}$ - температура $150^{\circ} \mathrm{C}$, концентрация раствора КОН $1 \mathrm{~N}$, длительность гидротермального синтеза 3 сут. Выявлено, что дегидратированный при 100-300 ${ }^{\circ} \mathrm{C}$ образец полученного цеолита полностью регидратируется в течение 10 ч и может быть использован в качестве адсорбента и катализатора.

\section{Список литературы}

1. Lassinantti M. Synthesis, characterization and properties of zeolite films and membranes. Microporous and mesoporous materials. 2001. № 5, P. 25-63.

2. Ramdas P., Cheeseman P.A., Deem M.W. A database of new zeolite-like materials. Phys. Chem. Chem. Phys. 2011. (1)3, P. 12407-12412.

3. Клюнтина А.Б., Прокофьев В.Ю., Гордина Н.Е. Влияние условий гидротермальной кристаллизации на синтез и свойства цеолита. Химия и хим. технология. 2013. Т. 56(3), С. 73-77. [Klyuntina A.B., Prokofev V.Yu., Gordina N.E. Influence of hydrothermal crystallization conditions on the synthesis and properties of zeolite. Chemistry and chemical technologies 2013. V. 56(3), P. 73-77. (in Russ.)]

4. Помазкина О.И., Филатова Е.Г., Пожидаев Ю.Н. Адсорбция катионов никеля (II) природными цеолитами. Физикохимия поверхности и защита материалов. 2014. Т. 50(3), С. 262-267. [Pomazkina O.I., Filatova E.G., Pozhidaev Yu.N. Adsorption of nickel (II) cations by natural zeolites. Physicochemistry of the surface and protection of materials. 2014. V. 50(3), P. 262-267. (in Russ.)]

5. Jhonson M., Oconnor D., Barnes P. Cation exchange, dehydration and calculation in clinoptilolite: in situ X-ray diffraction and computer modeling. J. Phys. Chem. 2003. (107), P. 942-951.

6. Kiseleva I.A., Ogorodova L.P., Melchakova L.V., Belitsky I.A., Fursenko B.A. Thermal stability, properties, dehydration processes and phase transition of some natural $\mathrm{Na}$,Ca-zeolites and cation-exchanged analogues. International conference «Patterns of evolution of the Earth's crust». St. Petersburg. 1996. Abstracts. Volume 2.

7. Colin S., Cundy P., Cox A. The hydrothermal synthesis pf zeolites: precursors, intermediates and reaction mechanism. Microporous and Mesoporous Materials. 2005. V. 82, P. 1-78.

8. Брек Д. Цеолитовые молекулярные сита. М.: Мир, 1976. 781 с. [Brek D. Zeolite molecular sieves. M., Mir, 1976. 781 p. (in Russ.)]

9. Treacy M. M., Higgins J. B. Collection of simulated XRD powder patterns for zeolites. England: Elsevier, 2001, 235 p.

10. Величкина Л.М., Коробицына Л.Л., Восмериков А.В., Радомская В.И. Синтез, физикохимические и каталитические свойства СВК-цеолитов. Журнал физической химии. 2007. T 81(10), C. 1814-1819. [Velichkina L.M., Korobitsyna L.L., Vosmerikov A.V., Radomskaya V.I. The synthesis and physicochemical and catalytic properties of SHS zeolites Russian Journal of Physical Chemistry A. 2007. V. 81(10), P. 1618-1622. (in Russ.)] 